\title{
The Effects of Rearing Density, Salt Concentration, and Incubation Temperature on Japanese Medaka (Oryzias latipes) Embryo Development
}

\author{
Bethany J. Rosemore and Cynthia A. Welsh
}

\begin{abstract}
Environmental stressors are often present when an aquatic species, such as the Japanese medaka (Oryzias latipes) fish, are developing. This study examined the effects of some of these environmental stressors (variation in rearing density, salinity, and incubation temperature) on medaka embryo development. The hypotheses are if rearing density is increased, then hatching success will also be improved, while having no effect on embryo development; if the salt concentration is increased to 20 parts per thousand (ppt), then the rate of development will also be increased; if temperature is increased to $32^{\circ} \mathrm{C}$, then the rate of development will also be increased. To determine the effects of variations in rearing density $(1,2,3$, and 4 eggs per well), the time of hatch was observed and noted. When testing variations in temperature $\left(24^{\circ}, 28^{\circ}\right.$, and $\left.32^{\circ} \mathrm{C}\right)$ and salinity $(0.3,10,15$, and $20 \mathrm{ppt})$, the onset of heartbeat and onset of retina pigmentation were observed. The original hypotheses were not all supported: as rearing density increased, success of hatch decreased; as salinity increased, only the rate of development for heartbeat increased; as temperature increased, the rate of development for both onset of the heartbeat and retina pigmentation also increased.
\end{abstract}

\section{Introduction}

B IOLOGICAL INDICATOR species help assess the health of many freshwater, coastal and marine ecosystems. ${ }^{1}$ The Japanese medaka fish is a biological indicator species that can speak to the outcome of many environmental stressors. Elevated water temperature, as a result of global climate change, is one such stressor found in many aquatic environments. ${ }^{2}$ An increase in water temperature would likely cause an increase in evaporation, which could, in turn, cause an increase in salinity and possibly population density.

Japanese medaka is a small freshwater fish that has a short lifespan and readily produces large numbers of eggs on a daily basis, thus making them popular for experimentation. ${ }^{3}$ They are commonly found in both brackish and freshwater ponds, marshes, and paddy fields of multiple Asian countries, including Japan and Korea. ${ }^{4}$ Freshwater is classified at a concentration of less than 0.5 parts per thousand (ppt), while brackish water is classified at $0.5-30$ ppt and salt water at a salt concentration of 30 plus ppt. $^{5}$

Medaka eggs hold value in research because they are of considerable size and have clear chorions, which allow for internal evaluation of embryo development. ${ }^{6}$ The medaka embryo undergoes thirty-nine stages of development. The onset of heartbeat, stage twenty-four, occurs at 1 day 20 hours post fertilization. The onset of retina pigmentation, stage twenty-eight, occurs at 2 days 16 hours post fertilization. ${ }^{7}$ The final stage of development, hatching, occurs at 7 days post fertilization (R. Johnson, Senior toxicologist, Environmental Protection Agency; personal communication, 2011). The embryo secretes an enzyme, on the $6^{\text {th }}$ day, from the hatching gland in order to soften the egg before fry emergence. ${ }^{8}$

The question is what effects do rearing, density, salinity, and temperature differentiation have on Japanese medaka (Oryzias latipes) embryo development? The first hypothesis is if rearing density is increased, then hatching success will also be improved, while having no effect on embryo development. This is based on observations made by scientists at the EPA lab in Duluth, MN (R. Johnson, personal communication, 2011). The second hypothesis is if the salt concentration is increased to $20 \mathrm{ppt}$, then the rate of development will also be increased due to observations made by Rosemore. ${ }^{9}$ The third hypothesis is if temperature is increased to $32^{\circ} \mathrm{C}$, then the rate of development will also be increased, based on observations made in a previous study by Rosemore and Scheuer. ${ }^{10}$

Cloquet Senior High School, Cloquet, Minnesota. 


\section{Methods and Materials}

To begin the experiment, rearing density was tested first, in order to determine the optimum rearing density per well (1 egg per well) for the temperature and salinity tests. Two 96well plates housed 48 replicates each of either 1, 2, 3, or 4 eggs. There were 48 wells per egg density, each incubated at $28^{\circ} \mathrm{C}$. Twenty-eight degrees Celsius was chosen as established in Rosemore and Scheuer's study ${ }^{10}$ to be the optimum temperature for reduced fungal growth and embryo mortality. Hatching was observed daily for 12 days. The number of hatched eggs per well was counted and recorded.

To test the effect of salt concentration on medaka embryo development, aquarium salt concentrations of $0.3 \mathrm{ppt}$ (freshwater), $10 \mathrm{ppt}, 15 \mathrm{ppt}$, and $20 \mathrm{ppt}$ (brackish water) were used. One egg was placed into each of the 48 wells per concentration. Stage 24 , the onset of the heart beat (1 day 20 hours), and Stage 28, the onset of retina pigmentation ( 2 days 16 hours), were observed and noted through photographs (Fig. 1) and counting the number of embryos that reached the specified stage at each given time. Observations were done before predicted stage time and until stage was reached.

Next, the effect of incubation temperature on medaka embryo development was evaluated at $24^{\circ}, 28^{\circ}$, and $32^{\circ} \mathrm{C}$. These temperatures were chosen in accordance with the optimum incubation temperatures found by Rosemore and Scheuer. ${ }^{10}$ The lowest mortality rate was found when medaka embryos were incubated in $28^{\circ} \mathrm{C} .{ }^{10}$ Forty-eight wells with one egg per well were used for each temperature. Tank heaters were placed in each of the water baths to achieve the needed temperature. Stage 24, the onset of the heart beat (1 day 20 hours), and Stage 28, the onset of retina pigmentation (2 days 16 hours) were again observed and noted through photographs and counting the number of embryos that reached the specified stage at each given time. Again, observations were made before predicted stage time and until stage was reached. A bar graph was constructed in Microsoft Excel using the data from the percentage of hatched eggs per density. All error-bar graphs and statistical analysis were done using the computer program SPSS.

\section{Results}

Medaka egg rearing density (1, 2, 3 and 4 eggs per well), salt concentration $(0.3,10,15$, and $20 \mathrm{ppt})$, and incubation temperature $\left(24^{\circ}, 28^{\circ}\right.$, and $\left.32^{\circ} \mathrm{C}\right)$ were varied in order to

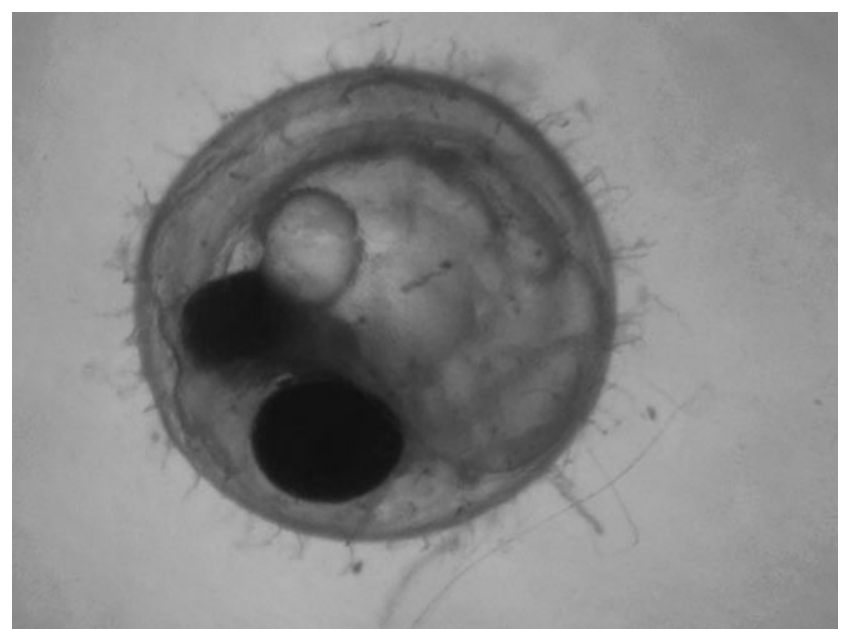

FIG. 1. Medaka embryo displaying all developmental stages observed in this study (eye pigmentation and heartbeat).

determine environmental factors that might affect medaka embryo development. When testing variations in temperature and salinity, the onset of heartbeat and retina pigmentation were documented. When testing rearing density, the time of hatch was recorded. To determine overall significant effects, a Univariate Analysis of Variance (ANOVA) was done using a value of $p<0.05$, indicating a $95 \%$ probability that the difference is due to the treatment. To determine differences between individual treatments, a post-hoc test was done.

When observing the effects of rearing density on hatching success, results showed that the rate of hatching was inversely proportional to rearing density. This effect was particularly pronounced between two and three eggs per well (Fig. 2). When observing the effects of rearing density on the time until medaka embryos hatched, increasing rearing densities caused an increase in time until hatch. Again, this effect was most apparent between two and three eggs per well (Fig. 3). Overall, the effect of rearing density on hatching rate and the time until hatch were statistically significant $(p<0.001)$. However, there was no statistical difference when comparing one and two eggs per well $(p<0.103)$ and three and four eggs per well $(p<0.372)$. A rearing density of two eggs per well had a significantly higher percentage of eggs hatched when
FIG. 2. Effects of rearing densities on hatching rate. Within a 12-day period, rearing densities of 1 and 2 eggs per well had hatching rates of $83 \%$ and $79 \%$, respectively, while densities of 3 and 4 eggs per well had hatching rates of $5 \%$ and $1 \%$, respectively.

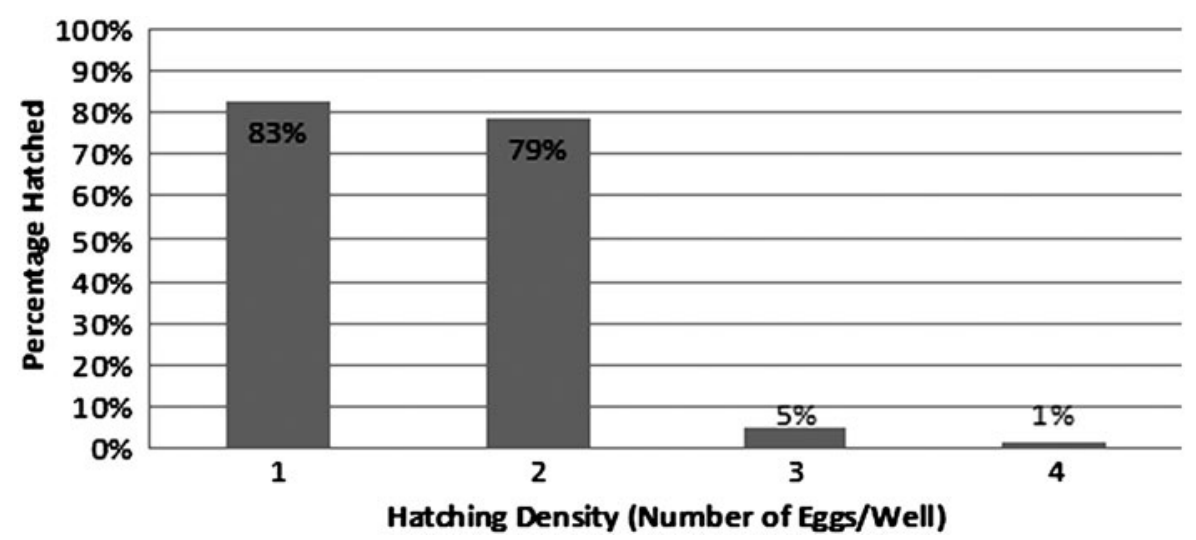




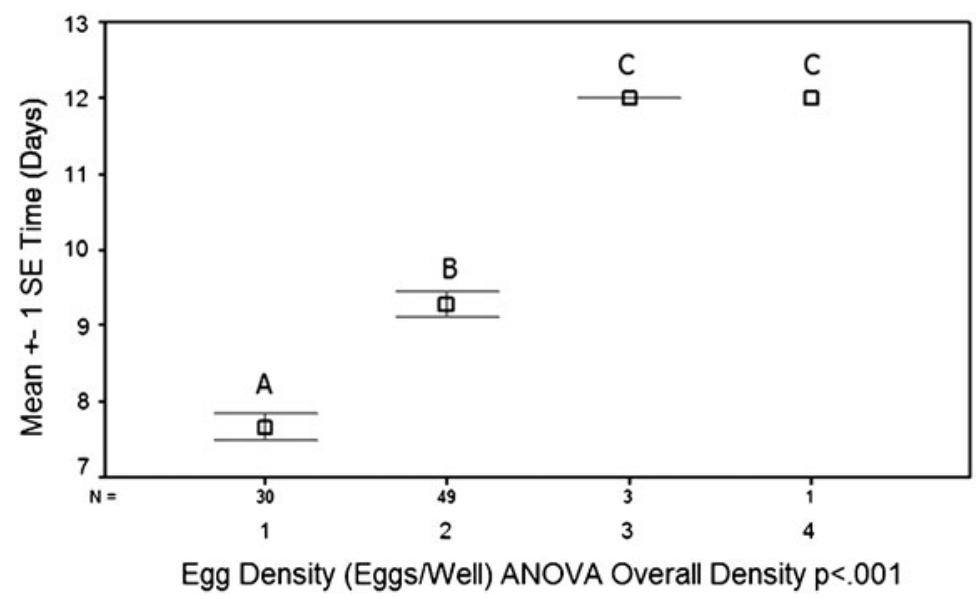

FIG. 3. Effects of rearing densities on time until hatch. Wells with 1 and 2 eggs had the lowest incubation time until hatch. With a rearing density of 1 egg per well, it took an average of 7.6 days until hatch. This is within the expected time until hatch (7 days). The few eggs that hatched in rearing densities of 3 and 4 eggs per well hatched in 12 days. compared to three eggs per well $(p<0.001)$. In the well with three eggs, only $5 \%$ of eggs hatched, while only $1 \%$ hatched in wells with four eggs. The remaining eggs did not hatch and eventually became fungus infected. Therefore, egg densities of three and four eggs per well caused high rates of embryo fatality.

When observing the effects of salt concentration on the time until the onset of heartbeat in the medaka embryo, results showed an inverse relationship between salt concentration and the time until the onset of heartbeat. This effect was particularly pronounced between a salt concentration of 15 and 20 parts per thousand (ppt). A salt concentration of $20 \mathrm{ppt}$ significantly reduced the time for the onset of the heartbeat $(p<0.01)$ (Fig. 4). When observing the effects of salt concentration on the time until the onset of eye pigmentation, no significant difference was found $(p<0.624)$ (Fig. 5). Therefore, salt concentration did have an inverse relationship with the onset of the heartbeat; however, no relationship was found with the development of eye pigmentation.

When observing the effects of incubation temperature on the time until the onset of heartbeat in the medaka embryo, results showed an inverse relationship between incubation temperature and the time until the onset of heartbeat. This effect was particularly pronounced between temperatures of $24^{\circ}$ and $28^{\circ} \mathrm{C}$. There was a significant reduction in time until development of the heartbeat when comparing $24^{\circ} \mathrm{C}$ to $28^{\circ}$ and $32^{\circ} \mathrm{C}(p<0.001)$ (Fig. 6). However, there was not a significant difference between $28^{\circ}$ and $32^{\circ} \mathrm{C}(p<1.00)$. When observing the effects of incubation temperature on the time until the onset of eye pigmentation, there was again an inverse relationship between time until development and incubation temperature. Another significant reduction in the time to develop eye pigmentation was seen when comparing $24^{\circ} \mathrm{C}$ to $28^{\circ}$ and $32^{\circ} \mathrm{C}(p<0.001)$ (Fig. 7). However, there was again not a significant difference between $28^{\circ}$ and $32^{\circ} \mathrm{C} \quad(p<0.869)$. Overall, an inverse relationship was found between incubation temperature and both development of the heartbeat and eye pigmentation.

\section{Conclusion/Discussion}

The original hypothesis was if the rearing density increases to four medaka eggs per well, hatching success would be improved. This hypothesis was not supported; as the number of eggs per well increased to three and four eggs per well, the number of eggs that hatched decreased significantly $(p<0.001)$. There was no difference between three and four eggs per well, thus indicating a possible upper limit of two eggs per well for optimum hatching success. There may be a connection between the hatching enzyme and why the eggs in higher rearing densities never hatched and ultimately became fungus infected. Before the embryo hatches,

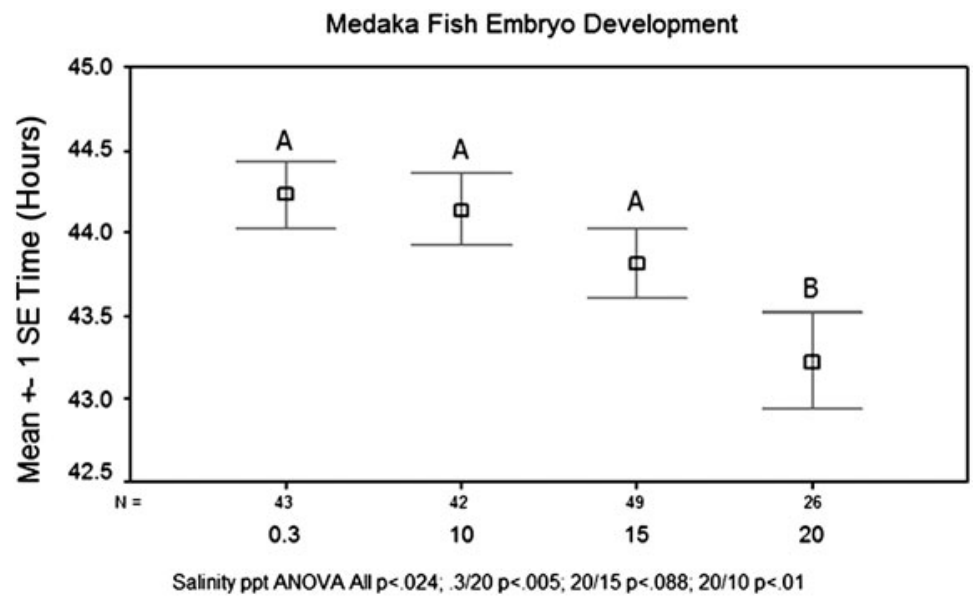

FIG. 4. Effects of salt concentration on the average time until the onset of heartbeat. Salt concentrations of $0.3,10,15$, and 20 parts per thousand (ppt) were tested. Twenty ppt significantly reduced the time for the onset of heartbeat $(p<0.01)$ with an average time of $43.2 \mathrm{~h}$ until the stage was reached. The expected time until the development of a heartbeat was $44 \mathrm{~h}$ post fertilization. Salt concentrations of $0.3,10$, and $15 \mathrm{ppt}$ took an average of $44.2,44.1$, and $43.8 \mathrm{~h}$, respectively, to develop a heartbeat. 


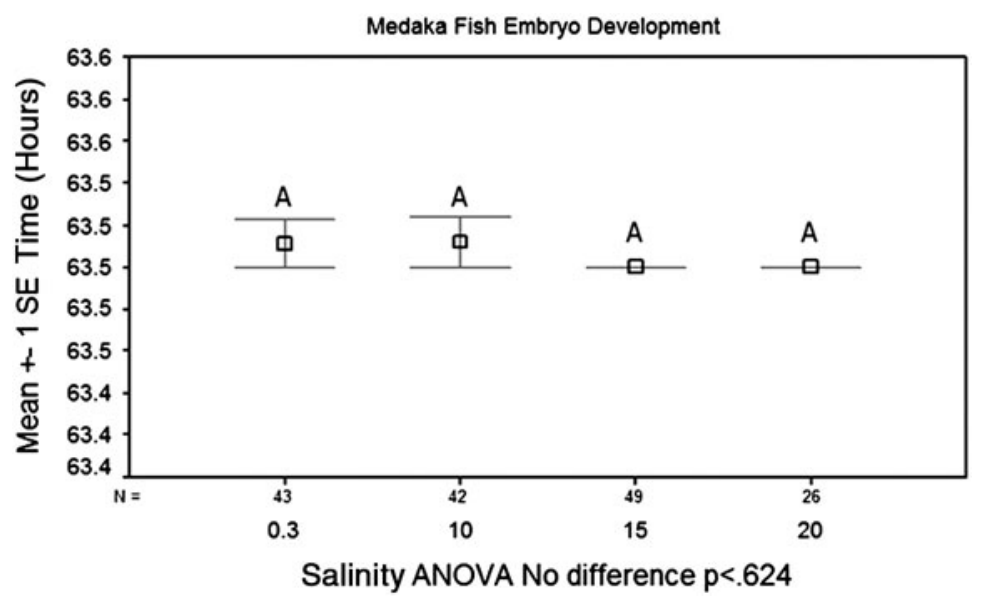

the hatching gland swells and secretes an enzyme that softens the egg cell for hatching. ${ }^{8}$ It was originally thought that the larger rearing densities (three and four eggs per well) would result in a higher hatching rate. When the embryo hatches, the hatching enzyme is released into the water and surrounds the neighboring embryos. This enzyme can then possibly soften the other eggs, thus accelerate hatching for the other embryos. Further testing would need to be done to determine the presence of the hatching enzyme within each hatching well.

One observation made in the hatching density experiment was the increased time until medaka embryos hatched when reared at higher densities $(p<0.001)$. There is a possible connection between the time until hatch, and differences in time of development or the growth rate. Zebrafish embryos develop naturally at different rates. ${ }^{11}$ This rate is subjected to greater differences later on in the developmental process. ${ }^{11}$ Therefore, the medaka embryos may also naturally develop at different rates and thus hatch at different times. Furthermore, a reduced growth rate has been observed in rainbow trout when rearing the fish at higher densities. ${ }^{12}$ This reduced growth rate could also occur in medaka embryos reared at higher densities, thus increasing the time until hatch. Further research needs to be done on the growth rate and developmental rates of medaka embryos.
The original hypothesis was that as salinity increases from 0.3 (freshwater), 10 and 15 ppt to 20 ppt (brackish water), then the rate of development for heartbeat and retina pigmentation would also increase. Medaka fish are known to survive in both a fresh and brackish water environment. ${ }^{5}$ (Therefore, as salinity increased within the normal range for a brackish water environment, it was hypothesized that rates of development would increase. This hypothesis was partially supported. Salinity did not affect the onset of retina pigmentation expressed by a $p$ value of $<0.624$. Yet, when salinity increased to a concentration of $20 \mathrm{ppt}$, the time of onset of heartbeat decreased significantly, expressed by a $p$ value of $<0.001$. Possibly, placing the embryos into the higher salt concentration of 20 ppt decreases the amount of energy necessary to maintain homeostasis, and provides more energy for development. The embryo must maintain equilibrium levels of salt and water. ${ }^{8}$ However, further research needs to be done to find the optimum salt concentration for development and where the upper limit resides.

The original hypothesis was that as incubation temperature increases from $24^{\circ}$ and $28^{\circ}$ to $32^{\circ} \mathrm{C}$, then the rate of development for both heartbeat and retina pigmentation would also increase. This hypothesis was supported. When looking at embryo development, the time it took for the embryos to develop a heart rate and retina pigmentation decreased
FIG. 6. Effects of incubation temperature on the time until the onset of heartbeat. Temperatures were tested at $24^{\circ}, 28^{\circ}$, and $32^{\circ} \mathrm{C}$. Eggs incubated at $24^{\circ} \mathrm{C}$ had the longest incubation period before the onset of heartbeat, with an average of $53.5 \mathrm{~h}$ post fertilization. This stage was expected to develop at $44 \mathrm{~h}$ post fertilization. Eggs incubated at $28^{\circ}$ and $32^{\circ} \mathrm{C}$ both on average took significantly less time to develop a heartbeat at $42 \mathrm{~h}$ post fertilization.

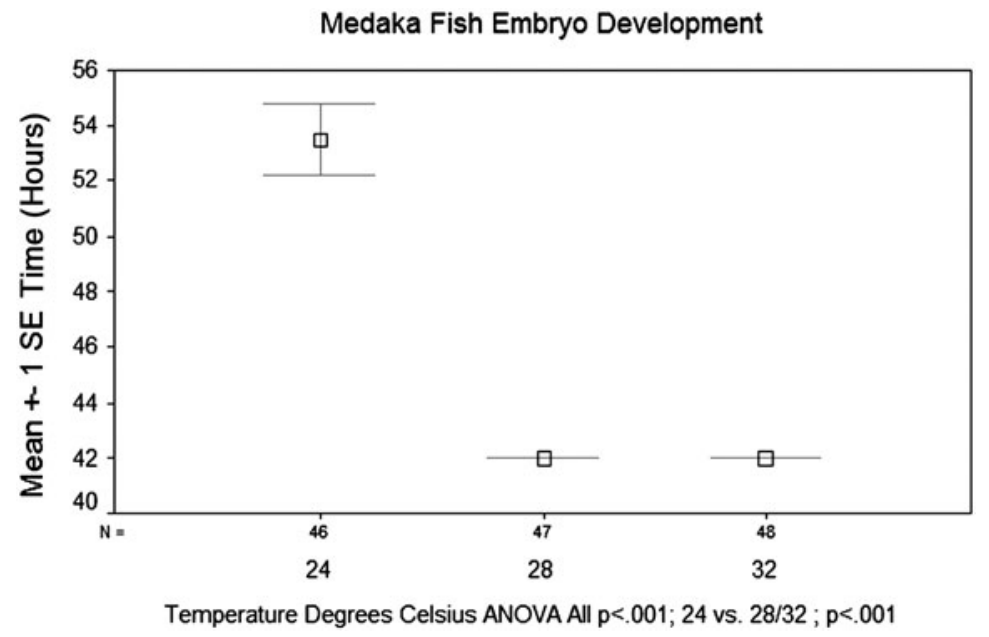




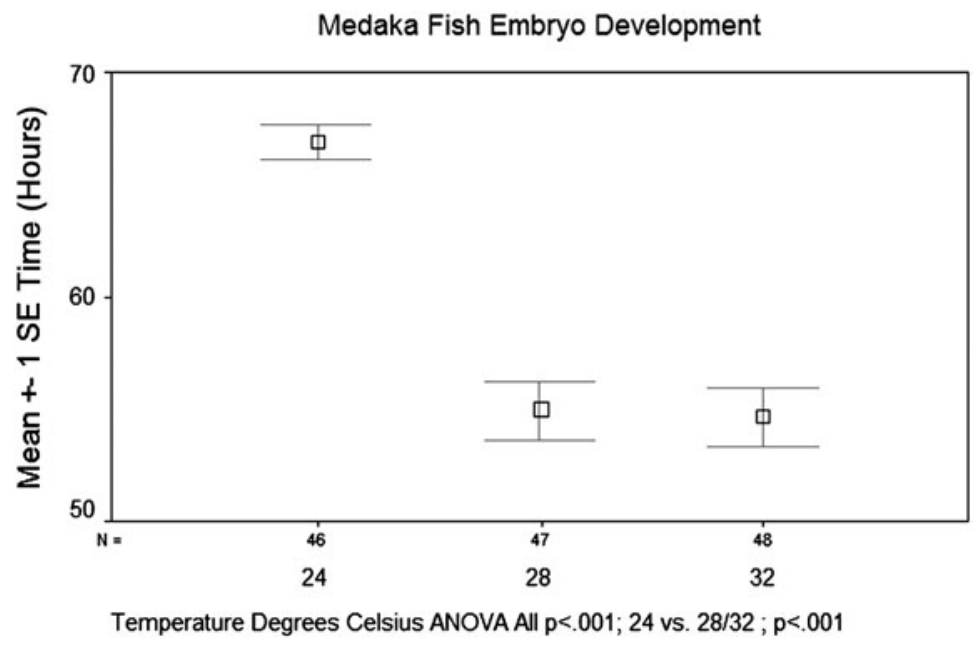

FIG. 7. Effects of incubation temperature on the time until the onset of retina pigmentation. Again, temperatures were tested at $24^{\circ}, 28^{\circ}$, and $32^{\circ} \mathrm{C}$. Eggs incubated at $24^{\circ} \mathrm{C}$ had the longest incubation period before onset of retina pigmentation, with an average of $66.9 \mathrm{~h}$ post fertilization. This stage was expected to develop at $64 \mathrm{~h}$ post fertilization. Eggs incubated at $28^{\circ}$ and $32^{\circ} \mathrm{C}$ both took on average significantly less time to develop a heartbeat at 54.9 and $54.7 \mathrm{~h}$ post fertilization, respectively $(p<0.001)$. significantly from $24^{\circ}$ to $28^{\circ}$ and $32^{\circ} \mathrm{C}(p<0.001)$. Applying the Q10 theory would explain this increased rate of development. This theory states that as temperature increases, many other biological processes would also increase. ${ }^{13}$ Therefore, possibly, as temperature increased, cellular metabolism increased allowing for faster development. There was not a significant difference between $28^{\circ}$ and $32^{\circ} \mathrm{C}$, therefore, the optimum temperature for the development of heartbeat and eye pigmentation falls somewhere above $24^{\circ} \mathrm{C}$. However, further research needs to be done to determine where the upper limit exists.

Research laboratories will benefit from knowing, in order to quickly raise healthy medaka embryos, that the rearing density should be either one or two eggs per well, in a salt concentration of $20 \mathrm{ppt}$, and a temperature of $28^{\circ} \mathrm{C}$. When evaluating the impact of global climate change, evaporation rates may increase, resulting in increased salinity, and egg densities, thus affecting the rate of embryo development. Embryos developing at higher temperatures appear to develop faster. Yet, at temperatures above $28^{\circ} \mathrm{C}$, fungal infections increased. ${ }^{10}$ Therefore, $28^{\circ} \mathrm{C}$ appears to be the optimum temperature for rearing medaka embryos.

\section{Acknowledgments}

This research would not have been possible without assistance from the Duluth Environmental Protection Agency scientists, Dr. Rodney Johnson, Dr. Kevin Flynn, and Kevin Lott, for their guidance and for supplying the materials needed to conduct this study. Melissa Olson, a high school English teacher at Prior Lake High School-Bridges Area Learning Center, in Prior Lake, Minnesota, performed the final edit before submission.

\section{Author Biographies}

Bethany Rosemore, previously a senior at Cloquet Senior High School, now attends the University of Rochester, New York. She has conducted scientific research since 7th Grade under the guidance of her teacher, mentor, and co-author, Dr. Cynthia Welsh. Rosemore's research has allowed her to compete multiple years at the Northeastern Minnesota Science Fair, Minnesota Academy of Science State Fair, and the regional and state Junior Science and Humanities Symposium. Rosemore earned state recognition through the Stockholm Junior Water Prize while placing second her senior year. While in high school, she advanced to six international science fairs, twice to Genius Olympiad, and four times to the Intel International Science and Engineering Fair (ISEF), held in various places all around the country. At these international events, Rosemore received a second place grand award at Genius Olympiad and a fourth place grand award and a second place in freshwater research special award at Intel ISEF. Her research was conducted in her basement, as her parents allowed her to turn part of the basement into a fish research laboratory. This project evaluated the effect of egg density, salt concentration, and incubation temperature on Japanese medaka (Oryzias latipes) embryo development. The data were analyzed through Excel graphs and statistical analysis that constructed error bar graphs and ran an analysis of variance (ANOVA) to compare the effects of the environments on the embryo development. She is now researching carbon photodegradation in streams under the guidance of Dr. Elizabeth Minor, an associate professor at University of Minnesota Duluth's Large Lakes Observatory, and graduate student Elizabeth Welsh. Rosemore has been accepted into the University of Rochester, New York, and plans to major in Biology and Environmental Science. She has been awarded a Research and Innovation Grant, thus allowing her to expand on her previous research throughout her undergraduate studies.

Dr. Cynthia Welsh teaches 7th Grade life science and a high school research class for Cloquet Public Schools. She has a life and earth science teaching degree, along with a Masters of Education and a Doctorate in Educational Policy and Administration. She is also the director of the NE MN and American Indian Regional Science and Engineering Fair.

\section{Author Contributions}

Bethany J. Rosemore performed this research as a part of her $11^{\text {th }}$ Grade Science Fair project. She presented her work at several conferences including the MN Academy of Science State Science Fair and the Tri-State Junior Science and Humanities Symposium. Her research was selected as one of the top water research papers for the 2012 MN Stockholm Junior 
Waterprize. She also was selected to present her research poster at the International Genius Olympiad in Oswego, New York, and the Intel International Science and Engineering Fair in Pittsburgh, PA.

Cynthia A. Welsh has a doctorate in Educational Policy and Administration from the University of Minnesota and is currently a science teacher at both Cloquet Senior High and Middle Schools. She is also the director of the NE Minnesota and American Indian Science and Engineering Regional Fair. She co-mentored Bethany Rosemore in her Medaka embryo research, as well as provided training, technical support and guidance throughout the research and writing process.

\section{Disclosure Statement}

No competing financial interests exist.

\section{References}

1. Environmental Protection Agency (EPA) (2011, January 31). Biological indicators of watershed health. U.S. Environmental Protection Agency. Available at http://www.epa .gov/bioiweb1/, accessed February 15, 2011.

2. Korner O, Kohno S, Schönenberger R, Suter MJ, Knauer K, Guillette LJ Jr, Burkhardt-Holm P. Water temperature and concomitant waterborne ethinylestradiol exposure affects the vitellogenin expression in juvenile brown trout (Salmo trutta). Aquatic Toxicol 2008;90:188-196.

3. Wittbrodt J, Shima A, Schartl M. Medaka-A model organism from the far East Nat Rev Genet 2002;3:53-64.

4. Roberts TR. Oryzias latipes, Japanese rice fish: Aquarium. Fish: Search FishBase. Available at http://www.fishbase .org/Summary/SpeciesSummary.php?id $=4669$, accessed December 22, 2008.

5. Finlay BJ, Esteban GF, Brown S, Fenchel T, Hoef-Emden K. Multiple cosmopolitan ecotypes within a microbial eukaryote morphospecies. Protist 2006;157,377-390.
6. Zha J, Wang Z, Schlenk D. Effects of pentachlorophenol on the reproduction of Japanese medaka (Oryzias latipes). ChemBiol Interact 2006;161,26-36.

7. Iwamatsu T. Stages of normal development in the Medaka Oryzias latipes. Mech Devel 2004;121:605-618.

8. Yamagami K. Mechanisms of hatching in fish: Secretion of hatching enzyme and enzymatic choriolysis. Integ Comp Biol 1981;21:459-471.

9. Rosemore B. What effect does an estuary (brackish water) environment have on Japanese Medaka (Oryzias latipes) embryo heart development? Symposium conducted at the meeting of the Minnesota Junior Science and Humanities Symposium. St. Paul, Minnesota, 2008.

10. Rosemore B, Scheuer B. The effect of temperature differentiation on embryo female-to-male sex reversal in the Japanese Medaka, Oryzias latipes. Symposium conducted at the meeting of the Minnesota Junior Science and Humanities Symposium. St. Paul, Minnesota, 2010.

11. Kimmel CB, Ballard WW, Kimmel SR, Ullmann B, Schilling TF. Stages of embryonic development of the zebrafish. Dev Dyn 1995;203:253-310.

12. Procarione LS, Barry TP, Malison JA. Effects of high rearing densities and loading rates on the growth and stress responses of juvenile rainbow trout. N Am J Aquac 1999;61:91-96.

13. Montagnes D, Kimmance S, Atkinson D. Using Q10: Can growth rates increase linearly with temperature? Aquatic Microb Ecol 2003;32:307-313.

Address correspondence to: Cynthia A. Welsh, B.S., M.Ed., Ed.D. Cloquet Senior High School $100018^{\text {th }}$ Street Cloquet, MN 55720

E-mail: cwelsh@cloquet.k12.mn.us 